\title{
Pure rate effect on compressive strength of concrete
}

\author{
Sangho Lee ${ }^{1}$, Kyoung-Min $\mathrm{Kim}^{1}$, and Jae-Yoel Cho ${ }^{{ }^{*}}$ \\ ${ }^{1}$ Seoul National University, Civil and Environmental Engineering Department, 1 Gwanak-ro, \\ Gwanak-gu, Seoul, Korea
}

\begin{abstract}
Dynamic Increase Factor (DIF) has been used to consider the compressive strength enhancement of concrete at the high and intermediate strain rates. However, DIF formulae suggested until now include the inertia effects as well as the rate effect because the DIF formulae has been assumed as a function of only the strain rate and the inertia effects cannot be avoided in tests at the high and intermediate strain rate region. Therefore, applying the DIF to design or analysis of social infrastructures may be dangerous because the resistance by the inertia effects are considered repetitively. In this study, an apparent DIF formula, which includes the inertia effects, was proposed by introducing terms related with the strain acceleration, which represent the axial and radial inertia effects. Then, a nonlinear regression analysis was conducted to determine the coefficients in the apparent DIF formula with results of Split Hopkinson Pressure Bar (SHPB) tests for concrete. Finally, the DIF formula excluding the axial and radial inertia effects was proposed for compressive strength of concrete at the high and intermediate strain rates.
\end{abstract}

\section{Introduction}

When a concrete structure under extreme events like explosion, car, ship, and aircraft crush is analysed or designed, Dynamic Increase Factor (DIF) has been used to consider the compressive strength enhancement of concrete in a constitutive equation. In general, DIF is obtained by conducting Split Hopkinson Pressure Bar (SHPB) test, but the inertia effects cannot be avoided in SHPB test for two reasons. First of all, the material properties of specimen tested are unknown, so a desirable incident wave minimizing the inertia effects cannot be determined. In addition, although the desirable incident wave is known, it is too difficult to obtain the incident wave intended precisely. As a result, test data of SHPB includes the inertia effects as well as the rate effect, so present DIF formulae of concrete compressive strength also include both effects. However, because the inertia effects are already considered in the equation of motion in Finite Element Analysis (FEA) for a structures under extreme loads, the analysis with DIF including the inertia effects, as called as apparent DIF, may give unconservative results by overestimating the dynamic strength of concrete. In this study, an apparent DIF formula, which includes the inertia effects, was

\footnotetext{
* Corresponding author: jycho@,snu.ac.kr
} 
proposed by introducing terms related with the strain acceleration, which represents the axial and radial inertia effects, and then, DIF by pure rate effect was proposed.

\section{DIF by pure rate effect}

\subsection{Inertia effects in apparent DIF}

The inertia effects in SHPB test were investigated analytically and experimentally, and it is found out that the axial strain acceleration, dimension, and density of a specimen are the key factors influencing the inertia effects [1-4]. Therefore, the inertia effects in SHPB test for concrete can be assumed by Eq. (1). $\Delta f_{\text {inertia }}, \ddot{\varepsilon}_{s}, \rho_{s}, d_{s}, l_{s}, k_{2}$, and $k_{3}$ denote the axial and radial inertia effects in SHPB, axial strain acceleration, density, diameter, length of a specimen, and coefficients for each inertia effect respectively.

$$
\Delta f_{\text {inertia }}=k_{2} \rho_{s} d_{s}^{2} \ddot{\varepsilon}_{s}+k_{3} \rho_{s} l_{s}^{2} \ddot{\varepsilon}_{s}
$$

And then, apparent DIF can be written such as Eq. (2) by separating the rate effect and the inertia effects, and by substituting Eq. (1) to Eq. (2), the apparent DIF can be assumed such as Eq. (3).

$$
\begin{gathered}
D I F_{\text {apparent }}=\frac{f_{c, \text { static }}+\Delta f_{\text {rate }}+\Delta f_{\text {inertia }}}{f_{c, \text { static }}} \\
=D I F_{\text {rate }}+\frac{\Delta f_{\text {inertia }}}{f_{c, \text { static }}} \\
D I F_{\text {apparent }}=D I F_{\text {rate }}+k_{2} \frac{\rho_{s} d_{s}^{2}}{f_{c, \text { static }}} \ddot{\varepsilon}_{s}+k_{3} \frac{\rho_{s} l_{s}^{2}}{f_{c, \text { static }}} \ddot{\varepsilon}_{s}
\end{gathered}
$$

Meanwhile, the rate effect can be assumed by a power function of loading rate like Eq. (4) in the rate process theory [5-6]. $\dot{\sigma}, \dot{\sigma}_{0}$, and $\beta$ denote loading rate, reference loading rate, and a constant in accordance with material property. In this study, the rate effect was assumed such as Eq. (5) like fib MC2010 [7]. $\dot{\varepsilon}_{s, \text { static }}$, strain rate in quasi-static test, was determined as $10^{-5} \mathrm{~s}^{-1}$ by referring ASTM C39/C39M-16b [8].

$$
\begin{gathered}
D I F_{\text {rate }}=\left(\frac{\dot{\sigma}}{\dot{\sigma}_{0}}\right)^{\frac{1}{\beta+1}} \\
D I F_{\text {rate }}=\left(\frac{\dot{\varepsilon}_{s}}{\dot{\varepsilon}_{s, \text { static }}}\right)^{k_{1}}
\end{gathered}
$$

Therefore, apparent DIF can be expressed such as Eq. (6).

$$
D I F_{\text {apparent }}=\left(\frac{\dot{\varepsilon}_{s}}{\dot{\varepsilon}_{s, \text { static }}}\right)^{k_{1}}+k_{2} \frac{\rho_{s} d_{s}^{2}}{f_{c, \text { static }}} \ddot{\varepsilon}_{s}+k_{3} \frac{\rho_{s} l_{s}^{2}}{f_{c, \text { static }}} \ddot{\varepsilon}_{s}
$$




\subsection{Concrete SHPB test}

\subsubsection{Specimen preparation}

In order to obtain apparent DIF data for regression of Eq. (6), concrete SHPB tests were conducted with $76.2 \mathrm{~mm}$ SHPB of Extreme Performance Testing Center (EPTC) in Seoul National University. Total 72 data for concrete SHPB test was obtained, and the variables of tests are listed on Table 1. I.D. of specimens is defined as Sxx-Dyy-Lzz, and xx, yy, and $\mathrm{zz}$ denote static strength from standard cylinder compressive test, diameter, and length of a specimen respectively. Specimens of SHPB test were placed in D50 $\times 100$ and D75 $\times 150$ moulds, and were cut and ground on age of 28 days. Table 2 shows concrete mix proportion. Maximum aggregate size is $13 \mathrm{~mm}$ for representability of small specimens.

Table 1. SHPB test condition.

\begin{tabular}{|c|c|c|c|c|c|c|}
\hline Variables & $\begin{array}{c}\text { Static } \\
\text { strength, } \\
\text { MPa }\end{array}$ & $\begin{array}{c}\text { Diameter, } \\
\mathbf{m m}\end{array}$ & L/D ratio & $\begin{array}{c}\text { Striker } \\
\text { length, } \\
\mathbf{m m}\end{array}$ & $\begin{array}{c}\text { Impact } \\
\text { vleocity, } \\
\mathbf{m} / \mathbf{s}\end{array}$ & $\begin{array}{c}\text { Pulse } \\
\text { shaper }\end{array}$ \\
\hline Values & $52,65,80$ & 50,75 & $0.5,1$ & $\begin{array}{c}200,300, \\
600\end{array}$ & $12-20$ & $\begin{array}{c}\text { Individual } \\
\text { design }\end{array}$ \\
\hline
\end{tabular}

Table 2. Concrete mix proportion.

\begin{tabular}{|c|c|c|c|c|c|c|c|c|c|}
\hline \multirow{2}{*}{$\begin{array}{c}\text { Static } \\
\text { strength, } \mathrm{MPa}\end{array}$} & \multirow{2}{*}{$\begin{array}{c}\mathbf{G}_{\max }, \\
\mathbf{m m}\end{array}$} & \multirow{2}{*}{$\begin{array}{c}\mathbf{W} / \mathbf{B}, \\
\%\end{array}$} & \multirow{2}{*}{$\begin{array}{c}\text { S/a, } \\
\%\end{array}$} & \multicolumn{6}{|c|}{ Unit weight, $\mathrm{kg} / \mathrm{m}^{3}$} \\
\hline & & & & $\mathbf{W}$ & $\mathrm{C}$ & SF & $\mathbf{S}$ & $\mathbf{G}$ & $\mathbf{S P}$ \\
\hline 52 & 13 & 34 & 44 & 176 & 520 & - & 715 & 918 & 5.2 \\
\hline 65 & 13 & 36 & 40 & 173 & 480 & - & 676 & 1014 & 4.8 \\
\hline 80 & 13 & 25 & 41 & 160 & 590 & 51.3 & 604 & 868 & 6.41 \\
\hline
\end{tabular}

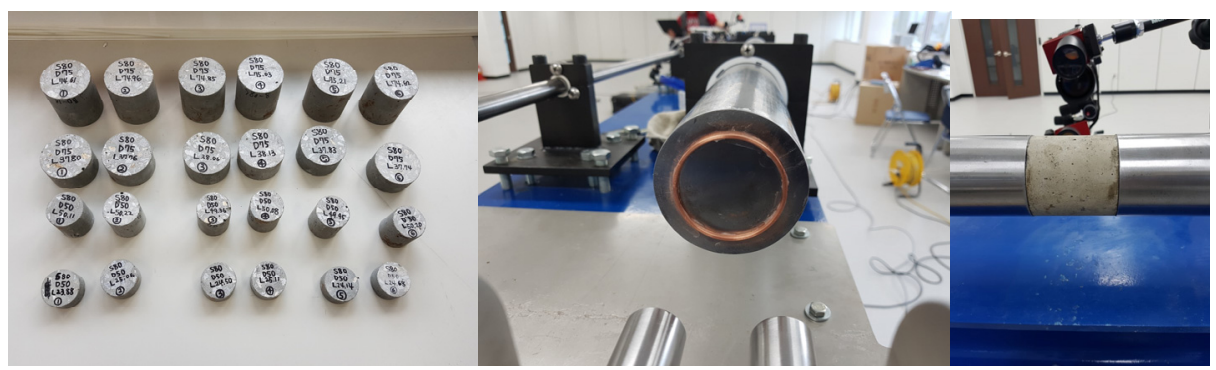

(a)

(b)

(c)

Fig. 1. (a) 85 MPa specimens of SHPB test; (b) Annular pulse shaper; (c) Positioning specimen.

\subsubsection{Test procedure}

Annular pulse shapers were used to reduce high frequency wave components due to the radial inertia effect of pulse shaper [9] as shown as Fig. 1. (b), and for each test, each annular pulse shaper was designed by pre-analyses using LS-DYNA. In order to minimize friction effect, the impact faces and interfaces of a pulse shaper and a specimen were lubricated by petroleum jelly as shown as Fig. 1. (b) and (c). Diameter of each bar component is $76.2 \mathrm{~mm}$, and the length of incident and transmitted bars is $5.5 \mathrm{~m}$. The striker length is ranged from $200 \mathrm{~mm}$ to $600 \mathrm{~mm}$, and the impact velocity was ranged from $12 \mathrm{~m} / \mathrm{s}$ to $20 \mathrm{~m} / \mathrm{s}$. 


\subsubsection{Test results}

Dynamic equilibrium was checked, and the raw data was transformed to stress and strain by 3 waves post-process. DIF was determined from the static strength of D150×300 standard cylinder specimen. Test results are shown in Fig. 2 and 3.

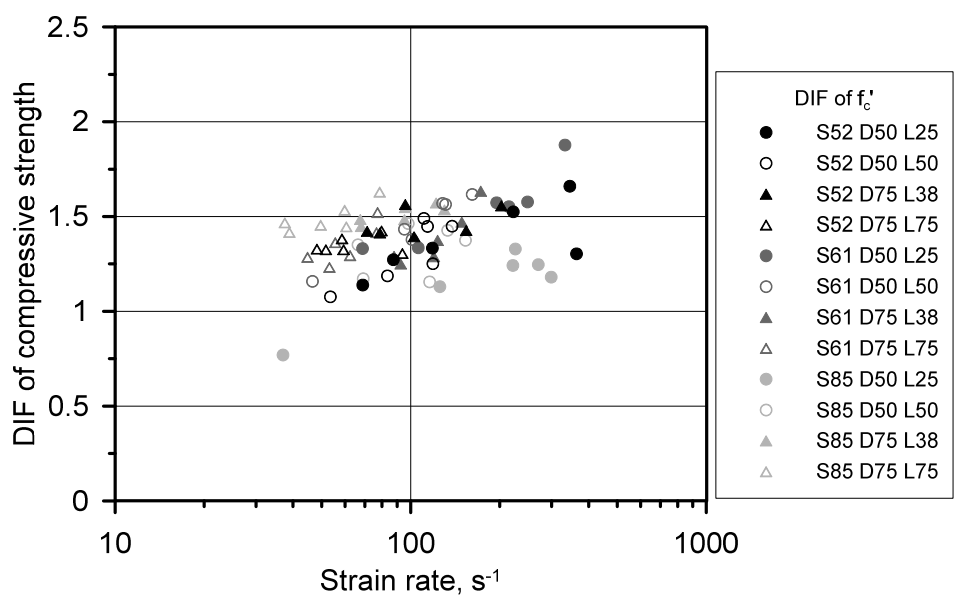

Fig. 2. Strain rate - DIF plot.

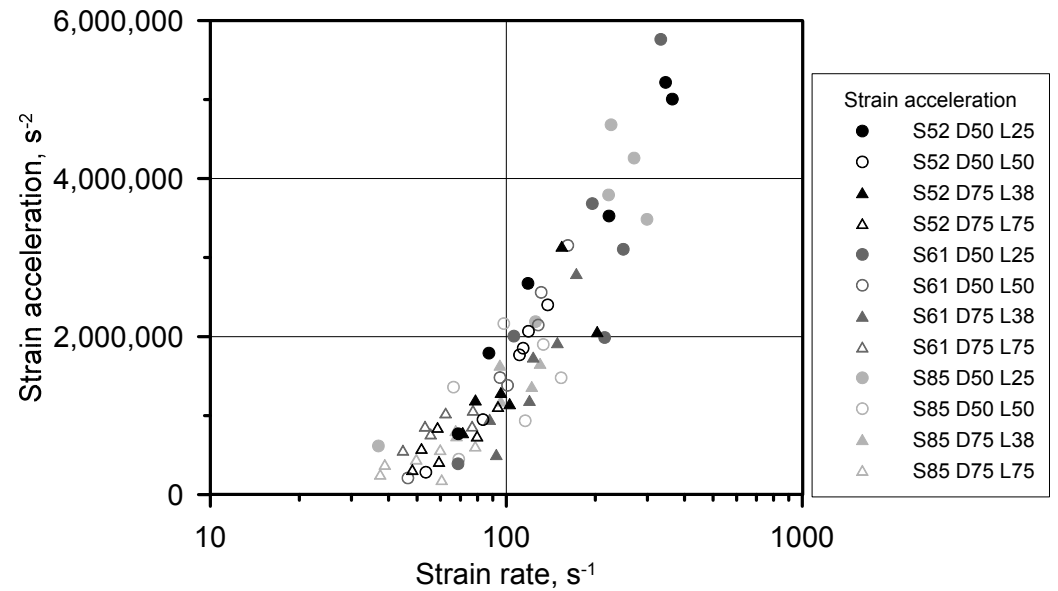

Fig. 3. Strain rate - strain acceleration plot.

\subsection{Regression analysis}

Nonlinear regression analysis was conducted for Eq. (6) to concrete SHPB test data. The objective function was the least square error such as Eq. (7). It was confirmed that there is the unique minimum point. Apparent DIF and DIF by pure rate effect were obtained such as Eq. (8) and (9) respectively. For dimensionless $k_{1}, k_{2}$, and $k_{3}$, units of variables were considered as Table 3.

$$
\Pi=\frac{1}{2} \sum_{i}\left\{D I F_{\text {test }, i}-\left[\left(\frac{\dot{\varepsilon}_{s, i}}{\dot{\varepsilon}_{s, \text { static }}}\right)^{k_{1}}+k_{2} \frac{d_{s, i}{ }^{2} \rho_{s, i}}{f_{c, s t a t i c, i}} \ddot{\varepsilon}_{s, i}+k_{3} \frac{l_{s, i}{ }^{2} \rho_{s, i}}{f_{c, s t a t i c, i}} \ddot{\varepsilon}_{s, i}\right]\right\}^{2}
$$




$$
\begin{gathered}
D I F_{\text {apparent }}=\left(\frac{\dot{\varepsilon}_{s}}{\dot{\varepsilon}_{s, \text { static }}}\right)^{0.0147}+0.3501 \frac{\rho_{s} d_{s}^{2}}{f_{c, \text { static }}} \ddot{\varepsilon}_{s}+0.4100 \frac{\rho_{s} l_{s}^{2}}{f_{c, \text { static }}} \ddot{\varepsilon}_{s} \\
D I F_{\text {rate }}=\left(\frac{\dot{\varepsilon}_{s}}{\dot{\varepsilon}_{s, \text { static }}}\right)^{0.0147}
\end{gathered}
$$

Table 3. Unit of variables.

\begin{tabular}{|c|c|c|c|c|c|c|}
\hline Variables & $\dot{\varepsilon}_{s}$ & $\ddot{\varepsilon}_{s}$ & $\rho_{s}$ & $f_{c, \text { static }}$ & $d_{s}$ & $l_{s}$ \\
\hline Units & $\mathrm{s}^{-1}$ & $\mathrm{~s}^{-2}$ & $\mathrm{~kg} / \mathrm{m}^{3}$ & $\mathrm{~Pa}$ & $\mathrm{~m}$ & $\mathrm{~m}$ \\
\hline
\end{tabular}

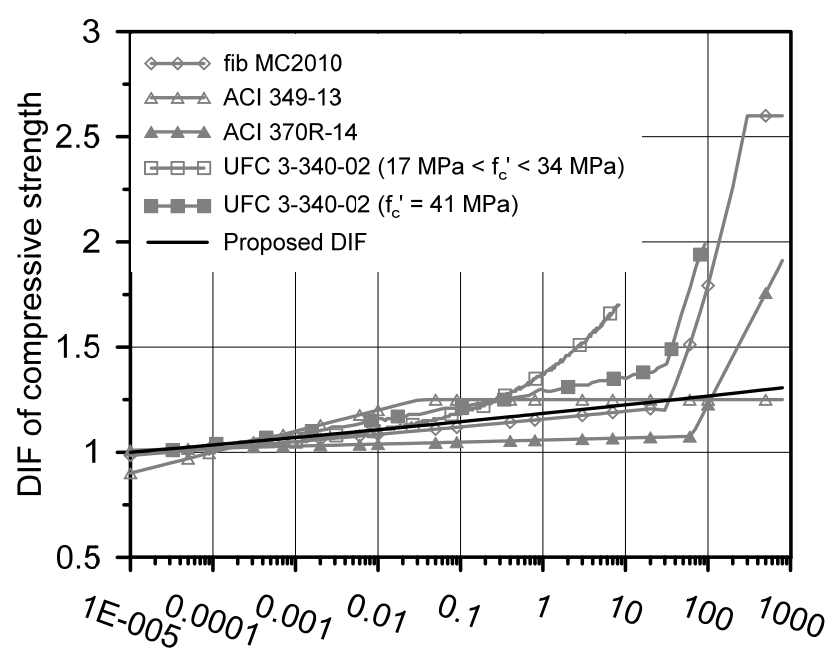

Strain rate, $\mathrm{s}^{-1}$

Fig. 4. Proposed and representative DIF. [7, 10-12]

Fig. 4 shows the proposed DIF by pure rate effect. The inertia effects become dominant as strain rate becomes high. First of all, DIF in fib MC2010 below transition strain rate is similar to proposed DIF, and it means that the steep increase of DIF is due to the inertia effects. In the case of DIF in ACI 349-13, the upper limit is just equal to 1.25 , so it is similar to proposed DIF at the $10-1,000 \mathrm{~s}^{-1}$ of strain rate region. For DIF of ACI 370R-14 also, because the transition strain rate is higher than those of the other DIF and the rate effect is underestimated, overestimation of the dynamic strength is started beyond about $100 \mathrm{~s}^{-1}$. Therefore, both DIFs of ACI are conservative relatively. Finally, DIF of UFC 3340-02 always overestimates the dynamic strength.

\section{Conclusion}

The inertia effects in apparent DIF by SPHB test were investigated, and DIF by pure rate effect was proposed. And also, following conclusions were derived.

1. DIF by pure rate effect was proposed for application in constitutive equation.

2. DIF of fib MC2010 is unconservative beyond transition strain rate, and this steep increase of DIF in fib MC2010 is due to the inertia effects. 
3. DIFs of ACI are conservative relatively, but DIF of ACI 370R-14 can derive unconservative dynamic strength beyond about $100 \mathrm{~s}^{-1}$ strain rate.

4. DIF of UFC 3-340-02 is unconservative at all strain rate region.

This research was supported by a grant (17CTAP-C069307-05) from Construction \& Transportation Technology Advancement Research Program funded by Ministry of Land, Transport and Maritime Affairs of Korean government and research fund of Doosan Yonkang Foundation.

\section{References}

1. E. Davies, S. Hunter, J. Mech. Phys. Solids, 11, 155-179 (1963)

2. D. Gorham, J. Phys. D: Appl. Phys., 22, 1888-1893 (1989)

3. M. Forrestal, T. Wright, W. Chen, Int. J. Impact Eng., 34, 405-411, (2007)

4. M. Zhang, H.J. Wu, Q.M. Li, F.L. Huang, Int. J. Impact Eng., 36, 1327-1334 (2009)

5. H. Mihashi, F.H. Wittmann, Heron, 25, 26-28 (1980)

6. J. Ožbolt, A. Sharma, H.W. Reinhardt, Int. J. Solids Struct., 48, 1534-1543 (2011)

7. fib Commission 8, "Code-type Models for Concrete Behaviour: State-of-the-art Report", 70 (fib Fédération internationale du béton, Lausanne, 2013)

8. ASTM C39/C39M-16b, "Standard Test Method for Compressive Strength of Cylindrical Concrete Specimens" (ASTM International, West Conshohocken, 2016)

9. W.F. Heard, B.E. Martin, X. Nie, T. Slawson, Exp. Mech., 54, 1343-1354 (2014)

10. ACI Committee 349, "Code Requirements for Nuclear Safety-Related Concrete Structures (ACI 349-13) \& Commentary" (American Concrete Institute, Farmington Hills, 2014)

11. ACI Committee 370, "Report for the Design of Concrete Structures for Blast Effects" (American Concrete Institute, Farmington Hills, 2014)

12. Unified Facilities Criteria (UFC) 3-340-02, "Structures to Resist the Effects of Accidental Explosions" (U.S. Department of Defense, Washington D.C., 2008) 